\title{
THE MANAGEMENT OF HYDATID DISEASE OF BONE AND JOINT
}

\author{
M. K. Booz, KUWAIT
}

From the Kuwait Orthopaedic Hospital

The treatment of hydatid disease of the skeleton is always a problem to orthopaedic surgeons because the condition is rare and seldom diagnosed clinically. The incidence in relation to all forms of hydatid disease in other organs of the body is remarkably low. In South America it is 2 per cent (Ivanissevich 1934), in Kuwait 4 per cent (El Gazzar and McCreadie 1962) and in Australia less than 1 per cent (Alldred and Nisbet 1964). Mistakes

TABLE I

Management of Twelve Cases of Hydatid Disease of Bone and Joint in Kuwait

\begin{tabular}{|c|c|c|c|c|c|c|c|}
\hline $\begin{array}{l}\text { Case } \\
\text { number }\end{array}$ & Nationality & Age & Sex & Site & $\begin{array}{l}\text { Pathological } \\
\text { fracture }\end{array}$ & $\begin{array}{l}\text { Method of } \\
\text { treatment }\end{array}$ & Result \\
\hline 1 & Kuwaiti & 28 & Male & Humerus & $\therefore$ & $\begin{array}{l}\text { Curettage, formalin } \\
\text { and bone graft }\end{array}$ & Healed \\
\hline 2 & Kuwaiti Bedouin & 23 & Male & Rib & - & Excision & No follow-up \\
\hline 3 & Kuwaiti Bedouin & 75 & Male & $\begin{array}{l}\text { Lower end } \\
\text { of femur }\end{array}$ & + & Conservative & $\begin{array}{l}\text { Fracture } \\
\text { united }\end{array}$ \\
\hline 4 & Kuwaiti Bedouin & 21 & Male & Fibula & - & Excision & Healed \\
\hline 5 & Syrian & 20 & Male & Knee & - & Synovectomy & No follow-up \\
\hline 6 & Kuwaiti Bedouin & 65 & Female & Tibia & + & $\begin{array}{l}\text { Curettage, formalin } \\
\text { and bone graft }\end{array}$ & Healed \\
\hline 7 & Kuwaiti Bedouin & 35 & Male & Tibia & + & $\begin{array}{l}\text { Curettage, formalin } \\
\text { and bone graft }\end{array}$ & Healed \\
\hline 8 & Kuwaiti Bedouin & 35 & Male & $\begin{array}{l}\text { Upper end } \\
\text { of tibia }\end{array}$ & - & Curettage and formalin & Healed \\
\hline 9 & Kuwaiti Bedouin & 45 & Male & Femur & + & $\begin{array}{l}\text { Curettage, formalin } \\
\text { and bone graft }\end{array}$ & Healed \\
\hline 10 & Kuwaiti & 28 & Male & Spine & - & Curettage and formalin & $\begin{array}{l}\text { Under } \\
\text { treatment }\end{array}$ \\
\hline 11 & Kuwaiti & 60 & Male & Pelvis & - & Curettage and formalin & No follow-up \\
\hline 12 & Syrian & 30 & Male & Spine & - & $\begin{array}{l}\text { Decompression and } \\
\text { brine }\end{array}$ & $\begin{array}{c}\text { Under } \\
\text { treatment }\end{array}$ \\
\hline
\end{tabular}

in diagnosis are common because it can mimic tuberculosis, acute arthritis, fibrocystic disease, chondrosarcoma and simple cyst. Lesions in the spine are always mistaken for tumour or tuberculosis (Fitzpatrick 1965). The orthopaedic surgeon may thus be confronted with hydatid daughter cysts welling up from a bone during biopsy.

In this paper the management of twelve cases met with in the Kuwait Orthopaedic Hospital over a period of ten years is discussed. In a previous study six cases were reported (Booz 1968); six new cases are included here. 


\section{MATERIAL}

The more important details concerning the twelve patients are summarised in Table I. Method of treatment-Conservative treatment was adopted in one case and excision of the diseased bone in two cases. In nine cases curettage and formalin swabbing was performed; autogenous and heterogenous bone grafts were used in four of these.

Results-Three patients operated on within the past year are not included as it is too early to report on the end-results. Two other patients could not be traced. The seven remaining patients have done well, six after operation and one with purely conservative treatment. All five pathological fractures in this group of seven patients have united; there has been no refracture and no recurrence of disease after operation on their extremities.

\section{CASE REPORTS}

Case 1-A Kuwaiti man aged twenty-eight presented in 1958 with a pathological fracture of the humerus (Fig. 1) and a diagnosis of monocystic bone disease was made. Hydatid disease was found at operation and an intramedullary nail was inserted (Fig. 2). The wound broke down. A second operation was performed, with thorough curettage. The fracture united, and there had been no recurrence when the patient was last seen in 1971.

Case 2-A South Arabian man aged twentythree had a swelling of the left fourth rib which was diagnosed as a tuberculous cold abscess. At operation it was found to be hydatid. The rib was excised and the wound healed by primary intention. The patient could not be traced for follow-up.

Case 3-A Kuwaiti man aged sixty-five was seen in 1961 for pain and swelling in the lower third of the right femur of five years' duration. The swelling was diffuse, firm and not tender but causing mild aching pain. There were

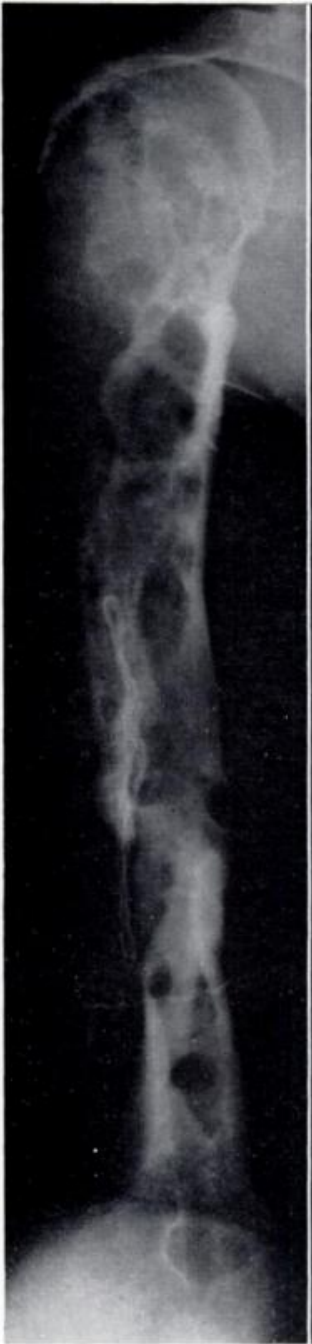

FIG. 1

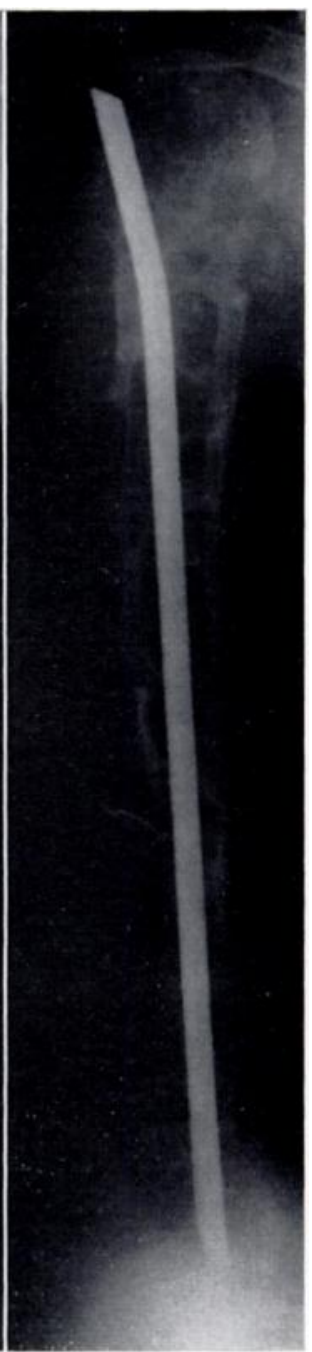

FIG. 2

Case 1. Figure 1-Extensive hydatid disease of the humerus. Figure 2-The appearance after curettage and insertion of an intramedullary nail. cystic changes in the lower femur (Fig. 3). The cortex was thin and there was no sclerosis. A soft-tissue mass showed some calcification. Hydatid disease was thought of, but a suspicion of malignancy invited biopsy which gave the true diagnosis. Conservative measures were adopted. In 1964 the patient sustained a pathological fracture (Fig. 4) which was successfully treated by a Thomas's splint for three weeks and weight-relieving caliper for eight months (Figs. 5 and 6). This man is being followed up regularly. Starting in 1970, aspiration of the popliteal fossa has been done every three months to relieve pain due to swelling and tension. On every occasion the aspirate was thick and the colour of tomato juice; it was full of small daughter cysts and microscopically scolices 
could be seen. In February 1972 aspiration was ineffective and a trocar and cannula were used to introduce a catheter. The fossa was evacuated and washed out with 30 per cent saline.

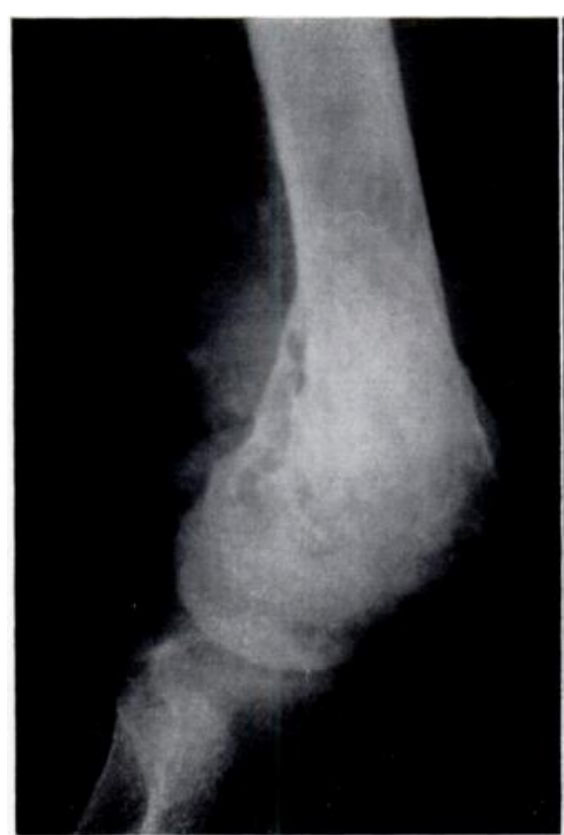

FIG. 3

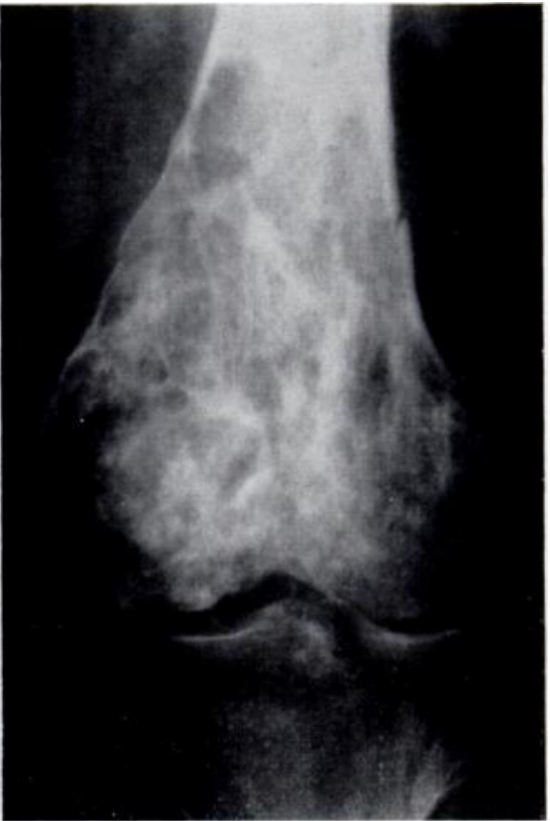

FIG. 4

Case 3. Figure 3-Hydatid disease of the lower end of the femur. Note the thin cortex, the cystic changes and the posterior soft-tissue shadow. Figure 4 Pathological fracture after two years of conservative treatment.

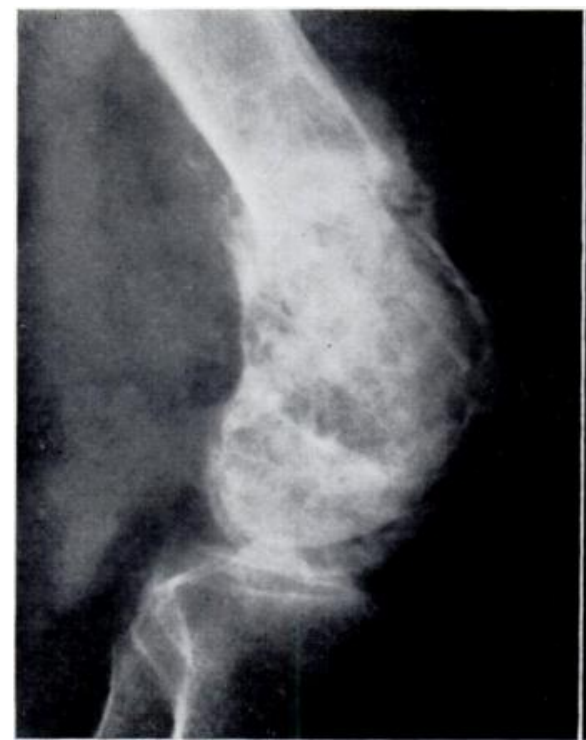

FIG. 5

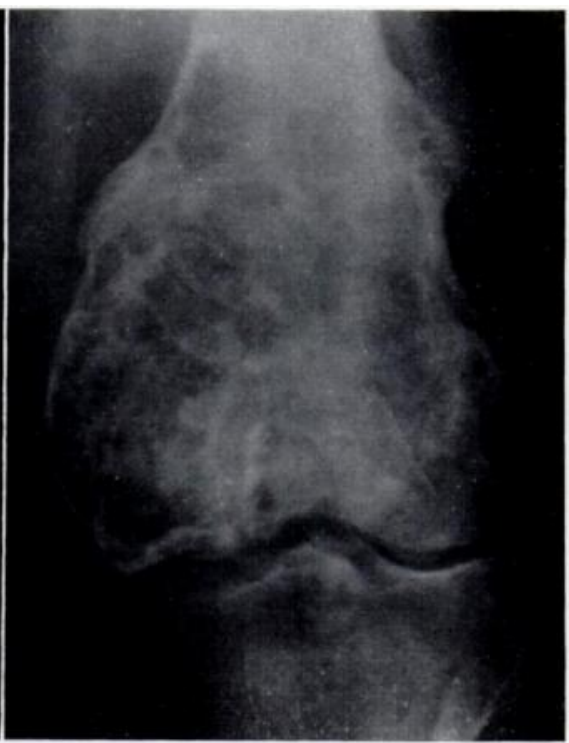

FIG. 6

Case 3--Radiographs showing healing of the pathological fracture, again with conservative treatment.

This man is heavily built and in good general health. He uses a single stick, which under the circumstances seems an excellent alternative to amputation at the age of seventy-five. 
Case 4-A man from South Arabia aged twenty-one presented with pain in the left leg. There was swelling of the fibula, the radiograph of which showed a cyst (Fig. 7). The diagnosis was made only at operation, when the affected segment was excised. Healing was uneventful and there has been no recurrence.

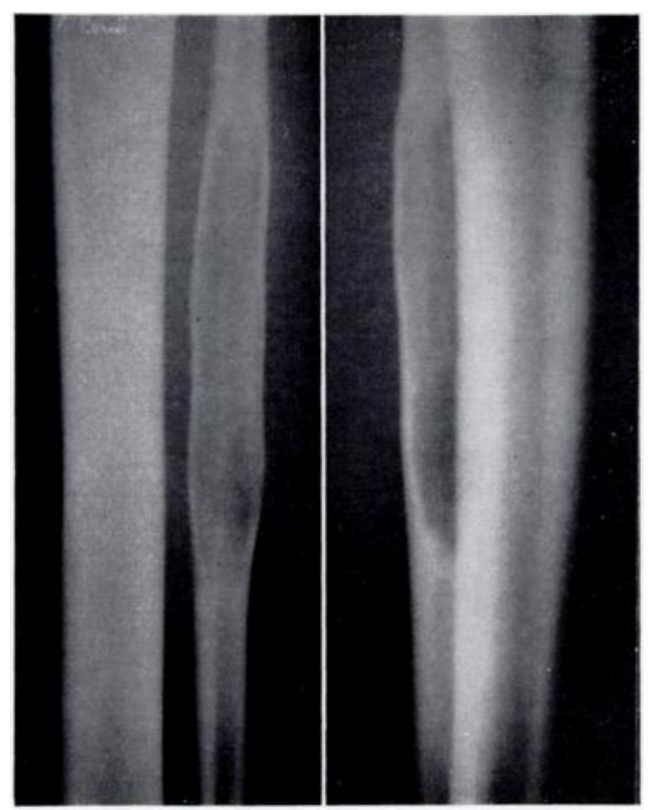

Fig. 7

Case 4- Hydatid disease of the upper part of the fibula.

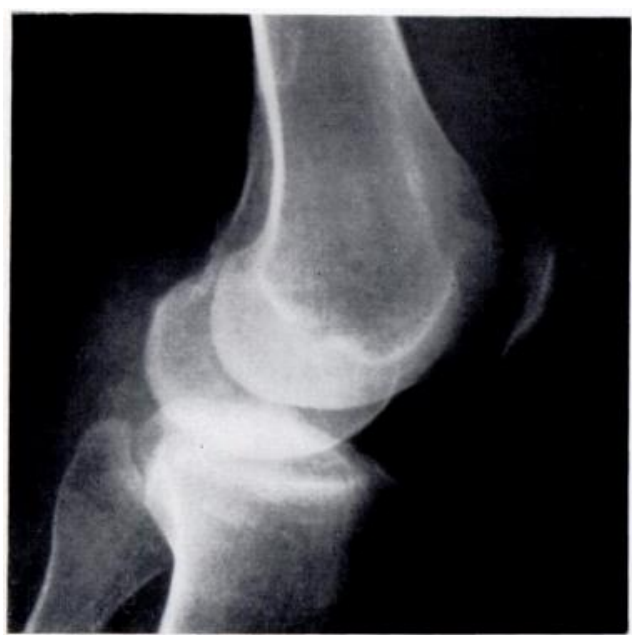

FIG. 8

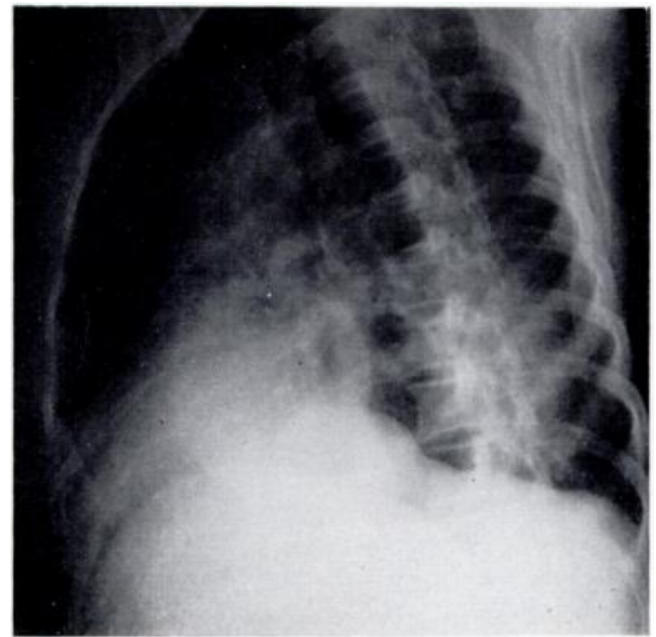

FiG. 9

Figure 8 - Case 5 . The lateral view of a knee affected by synovial hydatid disease. There were no definite bony changes in this unusual case. Figure 9-Case 6. The right lobe of the liver is elevated and shows a rounded mass on the upper surface due to a hydatid cyst.

Case 5-A Syrian man aged twenty presented in August 1964 with a history of "arthritis" of the knee for two years which had been treated by anti-rheumatic drugs. The eosinophil count was 4 per cent and the Casoni test was negative. The radiograph showed no definite bony lesion (Fig. 8). In our department a diagnosis of villonodular synovitis was made, but

VOL. 54 B, NO. 4, NOVEMBER 1972 


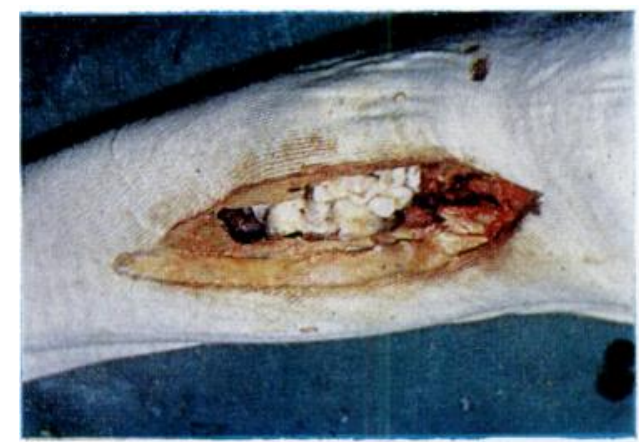

FIG. 10

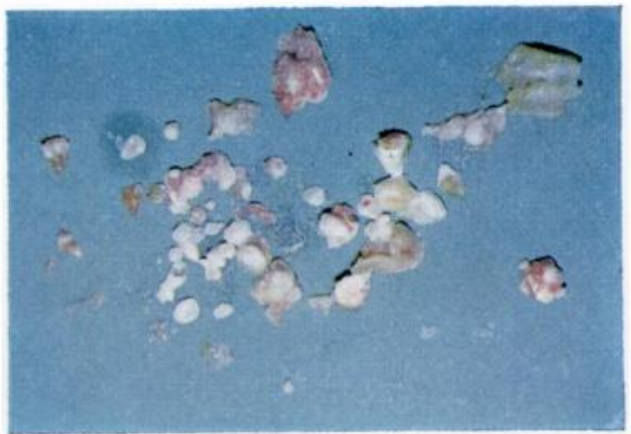

FiG. 11

Case 6. Figure 10--Hydatid cysts in the medullary cavity of the tibia. Figure 11-Hydatid daughter cysts taken out of the tibia.

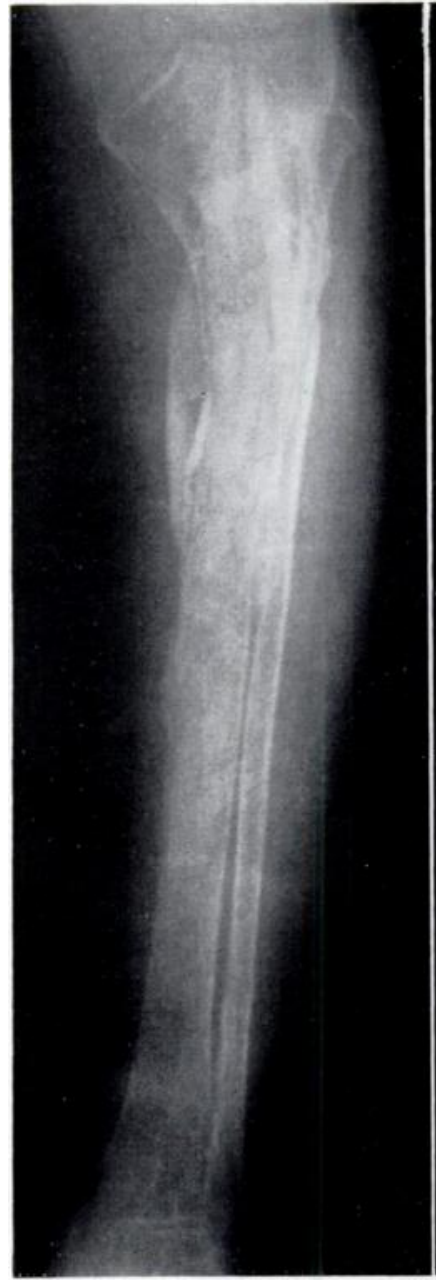

FIG. 12

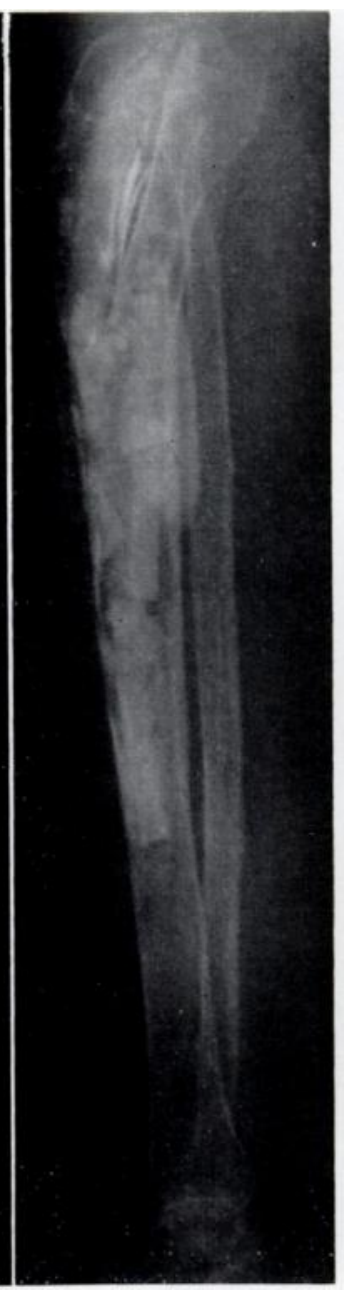
Case 6. Figure 12-The tibia showing the result of curettage, formalin swabbing and heterogenous
bone grafting. Figure 13-Pathological fracture of the upper end of the femur, due to secondary bone grafting. Figure 13-Pathological fracture of the upper end of the femur, due to secondary
carcinoma, six years after treatment of hydatid disease of the tibia. A pin and plate fixed the fracture prior to deep x-ray therapy.

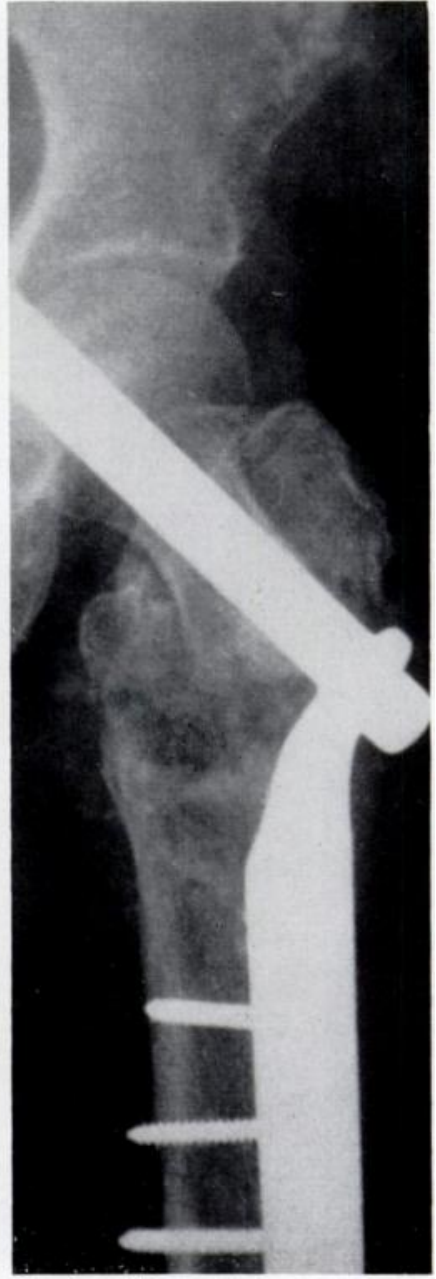

FIG. 13 
hydatid disease was found at operation. Total synovectomy was carried out and recovery was rapid. The range of flexion before operation was 0 to 110 degrees and five weeks afterwards 0 to 70 degrees. The patient then went to Syria and could not be followed up.

Case 6-A Kuwaiti woman aged sixty-five had a swelling of the upper end of the left leg for six weeks before admission to hospital. A radiograph showed a pathological fracture of the tibia which was the site of "cystic degeneration and honeycombing, with a soft-tissue swelling showing calcification". Hydatid disease was diagnosed. Casoni's test was positive and a radiograph of the chest showed a hydatid cyst of the liver (Fig. 9). At operation the tibial cortex was found to be very thin and the medullary cavity full of hydatid cysts (Fig. 10). The contents were scraped out (Fig. 11) and the cavity was washed with packs soaked in 10 per cent formalin, followed by packs of pure alcohol and saline washouts. Heterogenous bone grafts were packed in and around the tibia (Fig. 12). Because of delayed union the patient was supplied with a walking caliper. Having been lost to follow-up, she returned six years later with a pathological fracture of the upper end of the ipsilateral femur due to secondary carcinoma and was treated by pin and plate fixation and deep x-ray therapy (Fig. 13). The old hydatid lesion of the tibia was found healed and the pathological fracture united, but there was a simple fracture of the lower end due to a recent fall (Fig. 14).

Case 7-A Kuwaiti Bedouin man aged thirty-five came to hospital in January 1968 with a fractured tibia of three months' duration, sustained by falling from a camel. Radiographs showed a pathological fracture (Fig. 15). The diagnosis was thought to be fibrous dysplasia or malignant tumour. At biopsy hydatid disease was manifest. The cysts were removed, the huge cavity curetted, and packs of gauze soaked with 10 per cent formalin were inserted for a few minutes; this was followed by thorough cleansing with alcohol and lastly with saline. The medullary canal was then packed with iliac cancellous bone strips and chips. The wound became infected, however, and the fracture failed to unite. Appropriate antibiotics were administered but the infection persisted. Eleven months later an oblique osteotomy of the fibula was performed and the patient was allowed to bear weight fully in plaster. When last seen two years after the first operation, the wound was found healed and the fracture clinically solid and radiologically united (Fig. 16).

Case 8-A Kuwaiti soldier aged thirty-five was referred because of a painful left knee. There was palpable thickening over the medial tibial condyle. A radiograph showed an ill-defined area of rarefaction (Fig. 17) which was thought to be a giant-cell tumour. At operation hydatid cysts were found. The area was saucerised, curetted, and painted with 10 per cent formalin. Healing

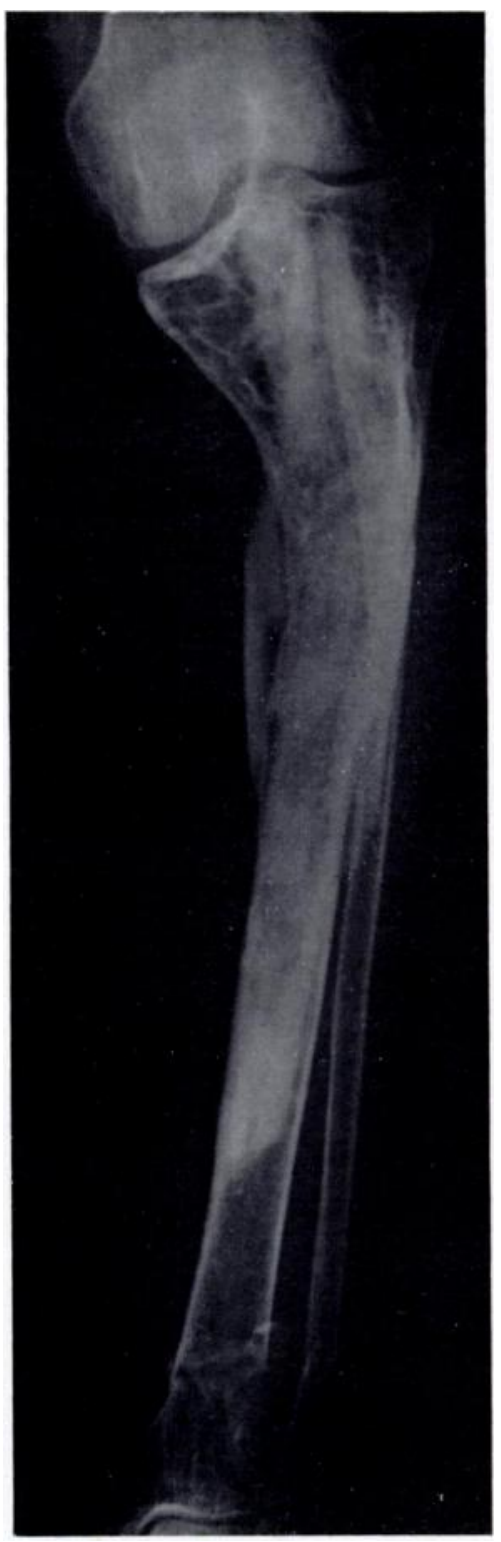

FIG. 14

Case 6-The tibia six years after heterogenous bone grafting for pathological fracture. The original fracture is united with some outward bowing, but there is a recent fracture of the lower third below the lesion due to a fall. 


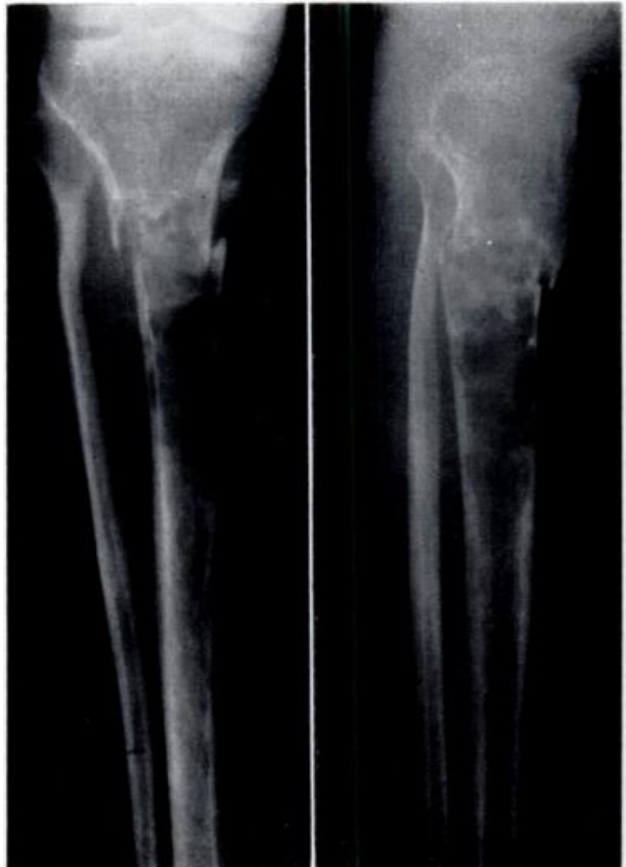

FIG. 15

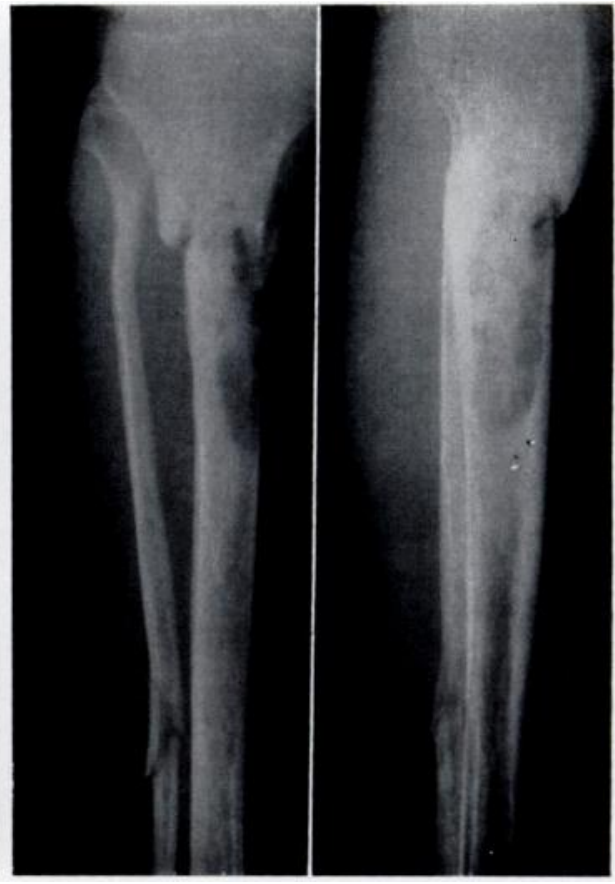

FIG. 16

Case 7. Figure 15-Pathological fracture of the upper end of the tibia due to hydatid disease. Figure 16-Union of the pathological fracture following bone grafting and later oblique osteotomy of the fibula.

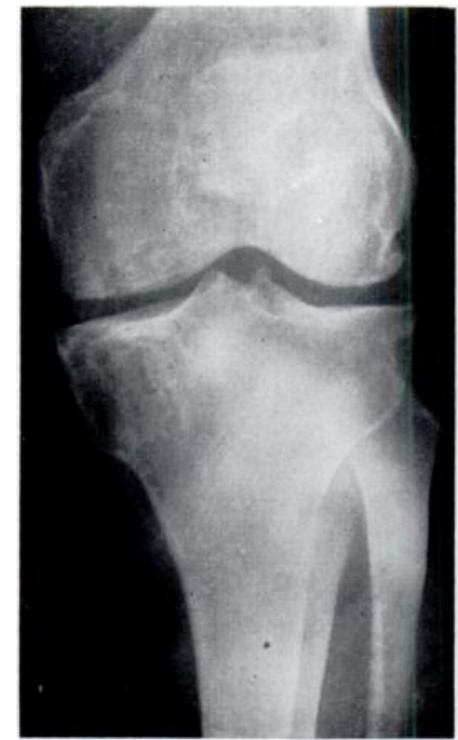

FIG. 17

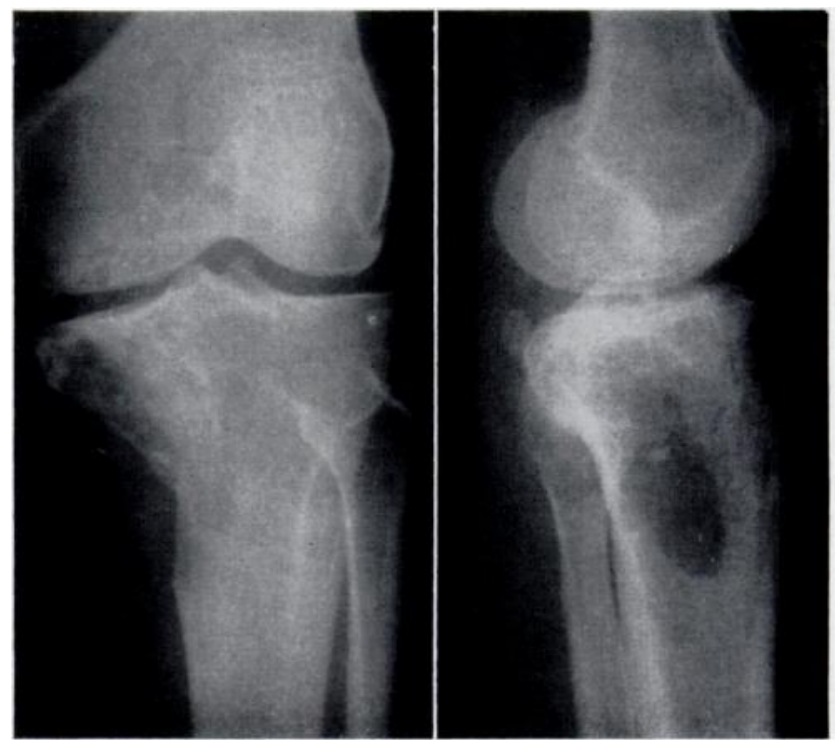

Fig. 18

Case 8. Figure 17-Hydatid disease of the medial condyle of the left tibia. Figure 18--The upper end of the tibia following operation by curettage and formalin. 
was by primary intention. There was no recurrence when he was examined a year later (Fig. 18).

Case 9-A Kuwaiti man aged forty-five living in the desert was admitted to hospital in September 1969 with an ununited fracture of the femur following a direct injury by a camel eight months before. Although Casoni's test was negative, hydatid disease was diagnosed.

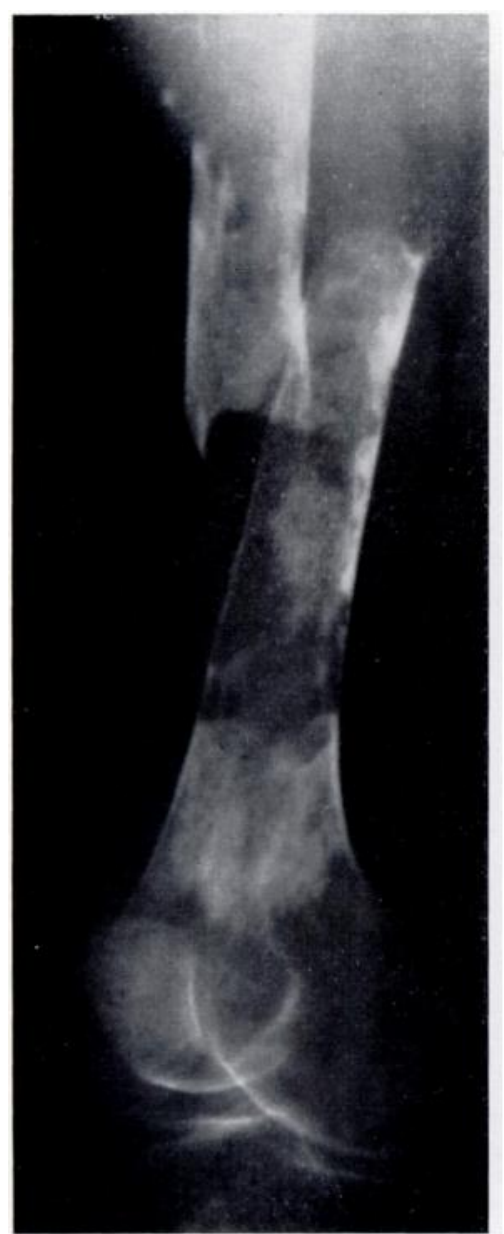

FIG. 19

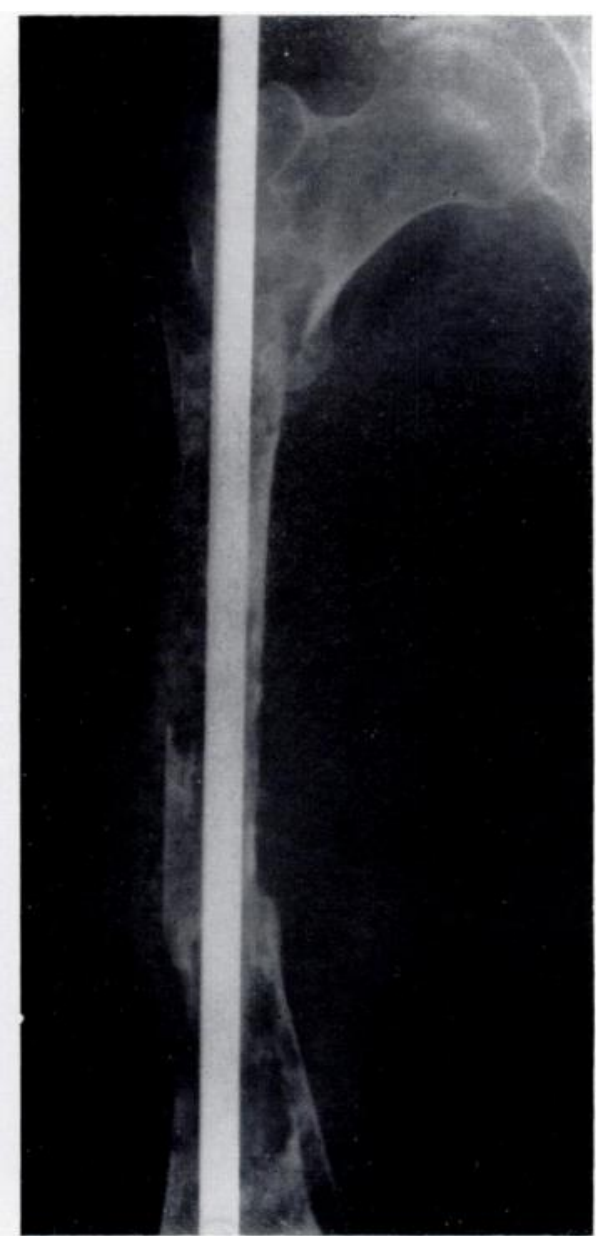

FIG. 20

Case 9. Figure 19-Pathological fracture of the femur from extensive hydatid disease. Figure 20--To show intramedullary nailing with autogenous and heterogenous bone grafting of the whole shaft.

There were two pathological fractures, one subtrochanteric and one of the shaft (Fig. 19). Treatment consisted of curettage, formalin swabbing, intramedullary nailing, and autogenous and heterogenous grafts (Fig. 20). Healing was delayed and sinuses broke out, but these finally closed after eighteen months and the fractures united.

Case 10-A Kuwaiti man aged twenty-eight, Bedouin and married, gave a history of weakness of both lower limbs for three months before admission to hospital. The weakness progressed to complete paraplegia two months from the onset. There was loss of sensibility up to the level of the umbilicus and there was retention of urine for four days before operation. The 


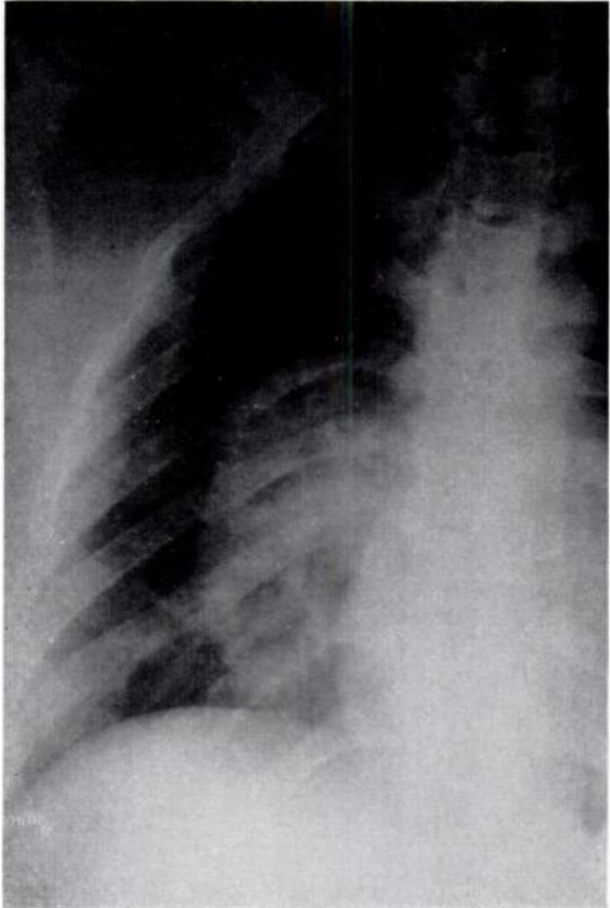

FIG. 21

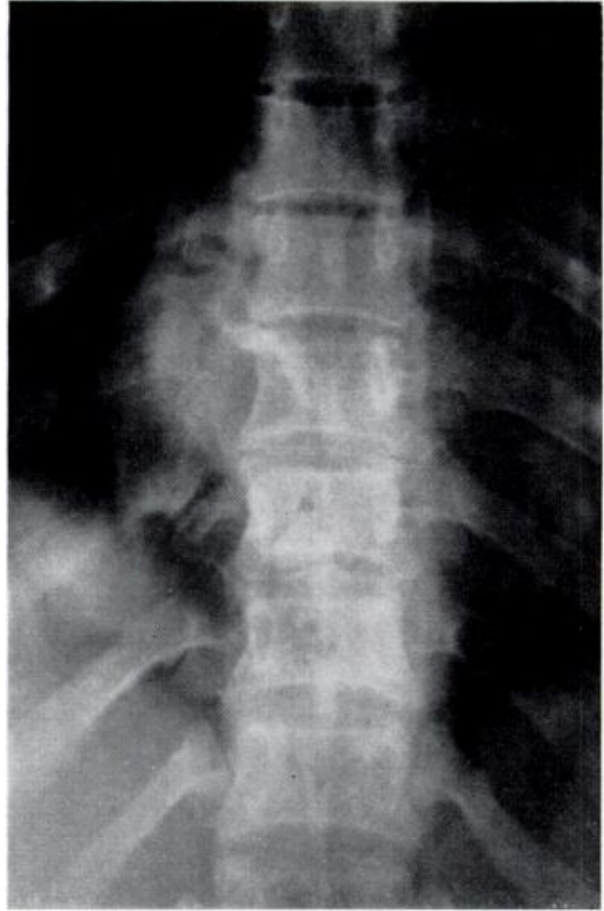

Fig. 22

Case 10. Figure 21-A radiograph showing a mass in the right mediastinum due to hydatid disease of the spine. Figure 22-A radiograph of the dorsal spine of the same case. Note the destruction of the right seventh and eighth pedicles and laminae and of the corresponding ends of the ribs.

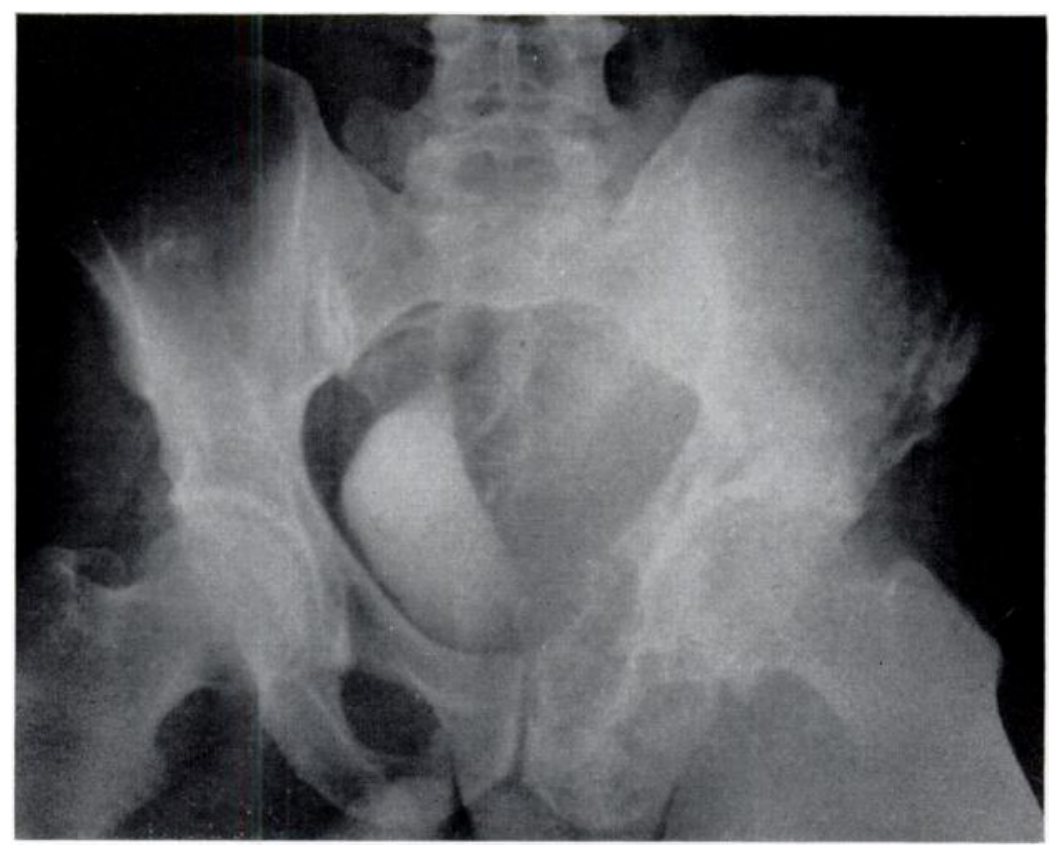

Fig. 23

Case 11-Hydatid disease of the left innominate bone with a hydatid cyst in the pelvis compressing the urinary bladder. 
radiograph showed a mediastinal expanding lesion mainly on the right side (Fig. 21) with destruction of the right pedicles and laminae of the seventh and eighth thoracic vertebrae and of the medial ends of the corresponding ribs (Fig. 22). The appearances were regarded as "malignant, with a remote possibility of tuberculosis". At operation daughter cysts came out of the laminectomy wound in large numbers from the spinal canal and vertebral bodies and from the posterior mediastinum. The whole area was swabbed with 10 per cent formalin after the removal of all available cysts. Healing of the wound was slow; it oozed thin fluid for one month and then closed completely. The patient regained control of urine on the tenth day after operation and sensibility gradually returned. It is, however, still premature to report the end-result.

Case 11-A Kuwaiti man aged sixty complained of pain and swelling in the left gluteal region of six months' duration. On examination a large spherical mass was found in the left iliac fossa and pelvis. A radiograph of the left innominate bone showed destruction and honeycombing. The urinary bladder was pushed aside and compressed by a spherical space-occupying lesion

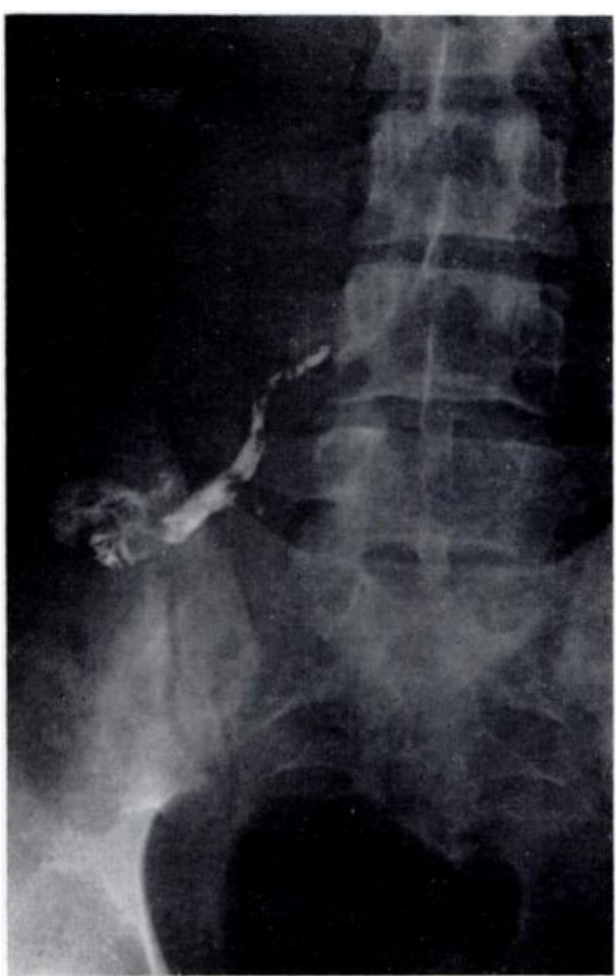

FIG. 24

Case 12-Sinogram showing dye leading to the fourth right lumbar transverse process.

(Fig. 23). Hydatid disease of the innominate bone associated with hydatid cyst of the pelvic cavity was diagnosed. This was proved by biopsy of the bone and removal of the cyst. Again it is still too early to comment on the end-result.

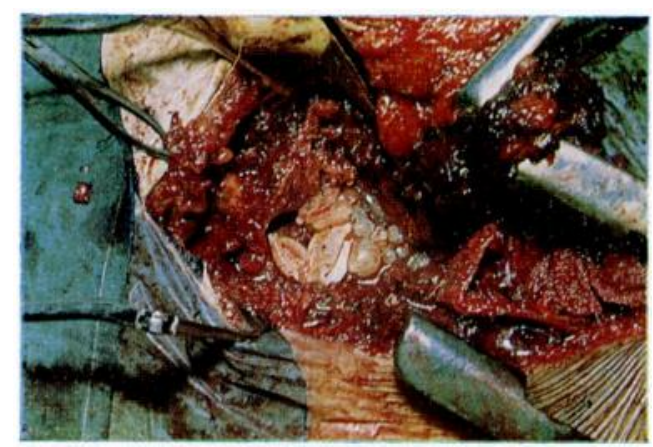

Fig. 25

Hydatid disease of the lumbar spine shown at operation. Note the number of daughter cysts around the dura mater and invading the surrounding muscles. (Case 12.)

Case 12-A Syrian man aged thirty presented with a sinus in the lumbar region leading to the right fourth transverse process (Fig. 24). The disease was thought to be tuberculosis and excision of the transverse process was performed. The sinus closed for two months but then

VOL. 54 B, NO. 4, NOVEMBER 1972 
broke down and the patient developed a cauda equina lesion. Laminectomy was performed. The bone was found thin and fragile and invaded by hydatid cysts that filled the spinal canal and spread into the muscles of the back (Fig. 25). Formalin could not be used because of its effect on nerve tissue. After operation 30 per cent brine was used to irrigate the area through a catheter under general anaesthesia, a method described by Parker and Chapman (1965). The paraplegia did not improve, however, and at the time of writing the sinus is still discharging.

\section{DISCUSSION}

The prevention of hydatid disease in man depends upon his ability to keep the gut of the dog population free from the cestode worm, echinococcus granulosa. In urban areas of Kuwait inspectors thoroughly examine the meat in the abattoirs. The sheep eaten in rural and desert areas by the Bedouins, however, are usually slaughtered privately. Furthermore, there is no proper control on the excreta of dogs, cats and other domestic animals. This explains why most of our patients are Bedouins or live in the desert.

Prevention of hydatid disease in sheep, cattle and camels should go hand in hand with control of the disease in dogs. The worms inhabit the small intestine of the dog, and the ova in dogs' excreta infect cattle, camels, sheep and man. To break this cycle in Bulgaria, all infected cattle are killed (Karaguiosov 1970).

The problem is complicated in vast desert areas with their uncontrollable population of Bedouins. Ten patients in this study are Bedouins who live or used to live in the desert under poor hygienic circumstances where municipal laws do not exist. No statistical values can be drawn from this study, which only reflects experience in our hospital and does not indicate the magnitude of the problem in Arabia.

Our experience in the management of hydatid disease of bone is limited to this series of twelve cases collected over a period of ten years. However, we are impressed with the results achieved with the curettage and bone grafting method. This is contrary to the experience of Pintilie, Panoza, Hatmanu and Fahrer (1966) and of Ottolenghi (1966), who advocate more radical operation with wide excision. The former recommend wide excision and bone grafting, while the latter has transplanted the whole femur. Each of them presented one case, and in both there was non-union at one end of the grafted or transplanted bone.

The operation of curettage and bone grafting is simple and if thoroughly done gives good results. Major operations are better reserved for selected cases in which the disease is advanced or not under control. There was a place for conservatism in one of our cases (Case 3 ) because the only alternative was amputation due to involvement of the popliteal fossa. Undoubtedly the best treatment is excision of the diseased bone, but this is only feasible at certain sites such as the rib or the fibula.

\section{SUMMARY}

1. Twelve cases of hydatid disease of bone seen in Kuwait over the last ten years are reported. Ten of the twelve patients were Bedouins.

2. Seven cases were followed up and the results of treatment are discussed.

3. Curettage, formalin swabbing and bone grafts were used as the treatment of choice.

4. There may be a place for a conservative approach in some cases; one such case reported here has been followed up for ten years.

5. The problem of prevention, especially in a Bedouin area, is briefly discussed.

I wish to thank my colleagues who kindly gave me their cases to include in this study: $\mathrm{Mr}$ A. Mutawee for Case 1, Dr M. A. El-Bahy for Case 8, Mr M. R. Hassanein for Case 9, and Assistant Professor L. Karaguiosov for Case 10 . 


\section{REFERENCES}

Alldred, A. J., and NisBet, N. W. (1964): Hydatid Disease of Bone in Australasia. Journal of Bone and Joint Surgery, 46-B, 260.

Booz, M. K. (1968): Hydatid Disease of Bone in Kuwait with Special Reference to Differential Diagnosis. Journal of the Kuwait Medical Association, 2, 27.

El Gazzar, A., and MCCreadie, D. W. A. (1962): Hydatid Disease in Kuwait. British Medical Journal, $2,232$. FitzPatrick, S. C. (1965): Hydatid Disease of the Lumbar Vertebrae. Journal of Bone and Joint Surgery, 47-B, 286.

Ivanissevich, O. (1934): Hidatidosis Osea. Buenos Aires: Amorrortu.

Karaguiosov, L. (1970): Personal communication.

Ottolenghi, E. C. (1966): Massive Osteoarticular Bone Grafts. Journal of Bone and Joint Surgery, 48-B, 646.

Parker, D., and Chapman, R. (1965): Hydatid Disease of the Innominate Bone. Journal of Bone and Joint Surgery, 47-B, 292.

Pintilie, D. C., Panoza, Gh., Hatmanu, D., and Fahrer, M. (1966): Echinococcosis of the Humerus. Journal of Bone and Joint Surgery, 48-A, 957. 